\title{
Independent Causal Contributions of Alpha- and Beta-Band Oscillations during Movement Selection
}

\author{
닌ok Brinkman, ${ }^{1}$ Arjen Stolk, ${ }^{2}$ Tom R. Marshall, ${ }^{1}$ Sophie Esterer, ${ }^{1}$ Poppy Sharp, ${ }^{1}$ H. Chris Dijkerman, ${ }^{3}$ \\ Floris P. de Lange, ${ }^{1}$ and Ivan Toni ${ }^{1}$ \\ ${ }^{1}$ Radboud University Nijmegen, Donders Institute for Brain, Cognition and Behaviour, Donders Centre for Cognitive Neuroimaging, 6500 HB Nijmegen, \\ The Netherlands, ${ }^{2}$ Helen Wills Neuroscience Institute, University of California, Berkeley, California 94720, and ${ }^{3}$ Utrecht University, Helmholz Institute, \\ Experimental Psychology, 3584 CS Utrecht, The Netherlands
}

To select a movement, specific neuronal populations controlling particular features of that movement need to be activated, whereas other populations are downregulated. The selective (dis)inhibition of cortical sensorimotor populations is governed by rhythmic neural activity in the alpha $(8-12 \mathrm{~Hz})$ and beta $(15-25 \mathrm{~Hz})$ frequency range. However, it is unclear whether and how these rhythms contribute independently to motor behavior. Building on a recent dissociation of the sensorimotor alpha- and beta-band rhythms, we test the hypothesis that the beta-band rhythm governs the disinhibition of task-relevant neuronal populations, whereas the alpha-band rhythm suppresses neurons that may interfere with task performance. Cortical alpha- and beta-band rhythms were manipulated with transcranial alternating current stimulation (tACS) while human participants selected how to grasp an object. Stimulation was applied at either 10 or $20 \mathrm{~Hz}$ and was imposed on the sensorimotor cortex contralaterally or ipsilaterally to the grasping hand. In line with task-induced changes in endogenous spectral power, the effect of the tACS intervention depended on the frequency and site of stimulation. Whereas tACS stimulation generally increased movement selection times, $10 \mathrm{~Hz}$ stimulation led to relatively faster selection times when applied to the hemisphere ipsilateral to the grasping hand, compared with other stimulation conditions. These effects occurred selectively when multiple movements were considered. These observations functionally differentiate the causal contribution of alpha- and beta-band oscillations to movement selection. The findings suggest that sensorimotor beta-band rhythms disinhibit task-relevant populations, whereas alpha-band rhythms inhibit neuronal populations that could interfere with movement selection.

Key words: alpha beta oscillations; motor imagery; movement selection; noninvasive brain stimulation; sensorimotor

Significance Statement

This study shows dissociable effects of $10 \mathrm{~Hz}$ and $20 \mathrm{~Hz}$ tACS on the duration of movement selection. These observations have two elements of general relevance. First, the finding that alpha- and beta-band oscillations contribute independently to movement selection provides insight in how oscillations orchestrate motor behavior, which is key to understand movement selection deficits in neurodegenerative disorders. Second, the findings highlight the potential of $10 \mathrm{~Hz}$ stimulation as a neurophysiologically grounded intervention to enhance human performance. In particular, this intervention can potentially be exploited to boost rehabilitation after neural damage by targeting the unaffected hemisphere.

\section{Introduction}

To choose an adequate movement in a given situation, multiple actions need to be considered to select the movement that best

Received March 16, 2016; revised June 9, 2016; accepted July 6, 2016.

Author contributions: L.B., A.S., T.R.M., H.C.D., F.P.d.L., and I.T. designed research; L.B., S.E., and P.S. performed research; L.B. contributed unpublished reagents/analytic tools; L.B. analyzed data; L.B., A.S., T.R.M., and I.T. wrote the paper.

This work was supported by The Netherlands Organisation for Scientific Research (NWO Brain and Cognition 433-09-248). We thank Ole Jensen and lan Cameron for useful comments on the manuscript.

The authors declare no competing financial interests.

This article is freely available online through the J Neurosci Author Open Choice option.

Correspondence should be addressed to Dr. Loek Brinkman, Radboud University Nijmegen, Donders Institute for suits current needs. It has been suggested that movement selection is implemented by mentally simulating alternative movements and evaluating their predicted outcomes (Wolpert and Ghahramani, 2000; Davidson and Wolpert, 2005; Shadmehr and Krakauer, 2008). When simulating a movement, specific neuro-

Brain, Cognition and Behaviour, Donders Centre for Cognitive Neuroimaging, $6500 \mathrm{HB}$ Nijmegen, The Netherlands. E-mail: loek.brinkman@gmail.com.

D01:10.1523/JNEUROSCI.0868-16.2016

Copyright $\odot 2016$ Brinkman et al.

This is an Open Access article distributed under the terms of the Creative Commons Attribution License Creative Commons Attribution 4.0 International, which permits unrestricted use, distribution and reproduction in any medium provided that the original work is properly attributed. 
nal populations controlling particular features of that movement need to be selected, whereas other populations need to be suppressed (Georgopoulos and Carpenter, 2015; Greenhouse et al., 2015; Murakami and Mainen, 2015). The selective (dis)inhibition of sensorimotor ensembles is thought to be governed by neural oscillation in the alpha- $(8-12 \mathrm{~Hz})$ and beta-band (15-25 $\mathrm{Hz}$ ) frequency range, where a decrease in spectral power in either of these rhythms is associated with an increase in spiking activity (Murthy and Fetz, 1992; Donoghue et al., 1998; Osipova et al., 2008; Voytek et al., 2010). During preparation, execution, and mental simulation of movements, the spectral power in both rhythms decreases bilaterally over the sensorimotor cortex, with the strongest decrease over the hemisphere contralateral to the used effector (McFarland et al., 2000; de Lange et al., 2008; Brinkman et al., 2014), providing a mechanism for selective activation of sensorimotor ensembles. However, it remains unclear whether these rhythms contribute independently to motor behavior.

Here we test how direct electrophysiological modulation of sensorimotor rhythms by means of transcranial alternating current stimulation (tACS) affects the duration of movement selection (Ozen et al., 2010; Ali et al., 2013; Helfrich et al., 2014; Schmidt et al., 2014; Neuling et al., 2015). The rationale for this electrophysiological intervention is based on the recent demonstration that alpha- and beta-band rhythms have distinct functional properties in the sensorimotor system. When selecting a movement from a set of biomechanically plausible actions, alpha-band power increases in the ipsilateral sensorimotor cortex, whereas beta-band power decreases in the sensorimotor cortex contralateral to the task-relevant effector (Brinkman et al., 2014). Those observations led to the hypothesis that an increase in alpha-band power inhibits cortical regions that interfere with movement selection (Jensen and Mazaheri, 2010; Brinkman et al., 2014), whereas a decrease in beta-band power disinhibits neuronal populations involved in the computations of movement parameters (Brown, 2007). Accordingly, we reasoned that enhancing alpha-band power over interfering neuronal populations should improve selection performance. By the same token, enhancement of beta-band power over task relevant neuronal populations should hamper task performance.

We tested this prediction in a group of healthy human participants $(N=38)$ performing a movement selection task that requires the integration of visual features of an object with current posture of the body and biomechanically plausible end-states of the arm (see Fig. 1A) (Verhagen et al., 2008, 2012; Dijkerman et al., 2009; Zimmermann et al., 2013). Participants were asked to imagine grasping a tilted cylinder with either their left or right hand and to report the end-state of the hand as soon as the imagined movement was completed. Motor imagery allows studying the simulation and selection of movements, removing the interpretational complications linked to cortical signals evoked by somatosensory reafference during movement execution, retrieval of arbitrary sensorimotor associations, or instructed-delay rules (Jeannerod, 1995; Jeannerod and Decety, 1995; Milner et al., 2001; de Lange et al., 2005; Rosenbaum et al., 2006; Wood and Goodale, 2011).

While participants selected how to grasp the tilted cylinder, short blocks ( $\sim 1 \mathrm{~min}$ ) of rhythmic electrical stimulation were applied to the sensorimotor cortex ipsilateral or contralateral to the grasping hand at either the alpha $(10 \mathrm{~Hz})$ or beta $(20 \mathrm{~Hz})$ frequency (doubleblind design; see Fig. 1B). This intervention is thought to enhance endogenous oscillatory activity in a frequency-specific manner (Ozen et al., 2010; Ali et al., 2013; Reato et al., 2013; Helfrich et al., 2014; Schmidt et al., 2014; Neuling et al., 2015). In this study, we investigated whether $10 \mathrm{~Hz}$ and $20 \mathrm{~Hz}$ stimulation affected the du- ration of the movement selection process and whether these effects depend on the hemisphere where stimulation was applied.

\section{Materials and Methods}

Participants. A total of 38 healthy right-handed human subjects participated in this study (mean $\pm \mathrm{SE}$, age $23 \pm 3$ years, 16 male). The study was approved by the local ethics committee, and a written informed consent was obtained from the participants according to the Declaration of Helsinki.

Experimental design and procedure. Participants were screened for contraindications for transcranial current stimulation (epilepsy, metal objects in the head, pregnancy, skin allergy, or recent participation in other brain stimulation experiments). Three rubber electrodes were attached to the participant's head, along the sagittal midline over the posterior parietal cortex, and laterally over left and right sensorimotor cortex (see Fig. 1). This montage allows for independent stimulation of each sensorimotor region. Following individual determination of stimulation intensity (see below), each participant performed 600 trials of a movement selection task ( $\sim 1 \mathrm{~h}$, see below for task description). We investigated the effects of $10 \mathrm{~Hz}$ and $20 \mathrm{~Hz}$ tACS applied during task performance over the left or the right sensorimotor cortex on the duration of task performance (within-subject design).

Movement selection task. Participants sat in a chair within reaching distance of a computer screen in an illuminated room where they performed a movement selection task. This task was similar to that used in a previous study, differing only in terms of the modality of response (Brinkman et al., 2014). Each trial started with the presentation of a fixation cross (duration 2-3 s, sampled from a uniform distribution) after which a stimulus appeared on the screen. The stimulus consisted of a black-white cylinder (length: $17.5 \mathrm{~cm}$; width: $3.5 \mathrm{~cm}$ ), which was presented on a gray background at the center of the screen and was oriented in 1 of 15 different orientations ( 24 degrees apart). The participant was asked to imagine grasping the middle third of the cylinder using wholehand prehension and to report whether their thumb was on the black or the white part of the stimulus (see Fig. $1 A, C$ ). As soon as the participants had selected how to grasp the object, they reported with a verbal response on which part of the stimulus their thumb was (saying out loud either "black" or "white"). The dependent measure of interest was the duration of the selection process, measured as the time between stimulus onset and the onset of the verbal response. Participants alternated the hand with which they imagined the grasping movement, in blocks of 10 trials, prompted by a visual cue (see Fig. $1 B$ ). This procedure prevented the emergence of stereotyped responses when repeatedly selecting movement with the same hand. The first trial of each block of 10 trials started with an additional fixation period of $5 \mathrm{~s}$, to emphasize the switch of hands and to allow for the tACS intervention to take effect. Every 60 trials, participants had a short break $(\sim 1 \mathrm{~min})$ and restarted the task when they were ready to continue. Stimuli presentation and verbal response onset detection were performed with Presentation software (Neurobehavioral Systems). The experimenter manually logged whether the subject answered "black" or "white." Trials in which voice-onset detection was incorrect (e.g., premature triggering by noise or trigger failure by hushed responses) were removed ( $3 \pm 4 \%$, mean \pm SD percentage of rejected trials).

Stimulation hardware and electrode placement. Stimulation was applied using a single-channel transcranial current stimulator (DC-stimulator PLUS, NeuroConn) and three flexible rubber electrodes (MedCat). Two electrodes $(5 \times 5 \mathrm{~cm})$ were placed over C3 and C4 (international EEG 10-20 system), as proxies for the left and right sensorimotor cortex (DaSilva et al., 2011). A larger reference electrode $(5 \times 10 \mathrm{~cm})$ was placed over parietal $\mathrm{Pz}$. This montage was based on previous studies that reported effects of tACS during imagined movements (Feurra et al., 2011, 2013). To reduce the impedance of the electrodes, the skin was first cleaned with alcohol and scrubbed with an abrasive gel (NuPrep, Weaver). To ensure proper contact between the skin and the electrode, a layer of conductive paste (Ten20, Weaver) was applied to both the electrode and the skin. These preparation steps typically took $\sim 1.5 \mathrm{~h}$ and resulted in low impedances of the electrodes ( $1 \pm 0.5 \mathrm{k} \Omega$; range, $0.4-2.3 \mathrm{k} \Omega$ ).

The waveform and intensity of the stimulation were controlled remotely with a custom signal generator. The output of the stimulator was 
routed to either the left or the right sensorimotor cortex using a custom switch box. Both the signal generator and the switch box were controlled by Presentation software (Neurobehavioural Systems).

Stimulation parameters. As we did not want our participants to notice the onset or offset of the stimulation, we determined for each participant the subjective threshold where participants either noticed a sensation on the skin or perceived phosphenes as a results of retinal stimulation (Herrmann et al., 2013; Laakso and Hirata, 2013). The $20 \mathrm{~Hz}$ tACS was applied to either the left or the right sensorimotor cortex while the stimulation intensity was incremented stepwise starting from $0.5 \mathrm{~mA}$ (peakto-peak). At each stimulation intensity, the participant was asked to indicate whether the participant noticed anything that could be related to the stimulation (forced choice). The stimulation intensity was incremented until stimulation was noticed or when an upper bound of $2.0 \mathrm{~mA}$ was reached. For the experiment, a stimulation intensity was used that was at least $0.1 \mathrm{~mA}$ below the individual thresholds (mean peak-to peak amplitude: $1.1 \pm 0.3 \mathrm{~mA}$; range: $0.4-1.9 \mathrm{~mA}$ ). This resulted in mean current densities of $45 \pm 13 \mu \mathrm{A} / \mathrm{cm}^{2}$ under the electrodes over the sensorimotor cortices ( $22 \pm 7 \mu \mathrm{A} / \mathrm{cm}^{2}$ for the electrode over Pz).

During the task, tACS was applied during right hand blocks only, as it has been shown that interhemispheric inhibition is strongest for movements with the dominant hand (Leocani et al., 2000; Liepert et al., 2001). The stimulation protocol was optimized to induce transient changes in endogenous alpha- and beta-band activity during stimulation while reducing homeostatic aftereffect (Feurra et al., 2011, 2013). We used short continuous blocks of stimulation that lasted for the duration of 10 trials $(\sim 1 \mathrm{~min}$, depending on the reaction times of the participant $)$ at constant stimulation intensity (no fade-in or fade-out). Stimulation blocks were interleaved with blocks involving the left hand (no stimulation) to reduce potential aftereffects on subsequent stimulation blocks. tACS was applied to the left or the right sensorimotor cortex using a sinusoidal waveform in either the alpha $(10 \mathrm{~Hz})$ or the beta $(20 \mathrm{~Hz})$ frequency range. In addition, a control condition was included were no stimulation was applied, resulting in five different stimulation conditions (see Fig. 1B). In total, participants performed 60 blocks of 10 trials, where stimulation was applied in 24 of the 30 right hand blocks (cumulative duration of stimulation $<30$ $\mathrm{min}$, total charge density $<0.14 \mathrm{C} / \mathrm{cm}^{2}$ ). Neither the subject nor the experimenter was aware of the order of the stimulation conditions (double-blind), where every five consecutive stimulation blocks contained all five stimulation conditions, in pseudo-random order.

During the breaks and after the experiment, participants were asked whether they noticed anything related to the stimulation (sensation on the skin, phosphenes, or otherwise). With two exceptions, none of the participants noticed anything related to the stimulation. One participant indicated that she occasionally felt a tingling sensation underneath the electrodes, and another indicated that he saw phosphenes. In both cases, these sensations were reported in only one of the blocks. None of the participants noticed that the stimulation occurred during right hand trials only, nor could they distinguish the side or the frequency of the stimulation.

Data analysis. To verify that participants were engaged in movement selection, we investigated whether the reported manner in which participants grasped the object was consistent with the biomechanical constraints of the body. These constraints predict that stimuli with certain orientations afford only one manner in which the object can be grasped (exclusively underhand or exclusively overhand grip), whereas stimuli with other orientations can be grasped equally well with either grip type (underhand and overhand grip). We refer to the latter stimulus orientations as "switch points," as the preferred grasping switches from black to white (or vice versa). Switch points are defined as the orientations that lead to maximal variability in how they are grasped (50\% black, 50\% white). Those orientations were determined separately for all participants, by fitting a sine-wave to the data points of the indicated grip types (explained in detail by Brinkman et al., 2014). The presence of switch points at biomechanically plausible orientations was taken as evidence that the participant was engaged in movement selection. Moreover, the specific orientation of the switch points should differ for selecting actions with the left and right hands (mirror images). Five participants (outside the set of 33 participants considered in this report) did not show distinct switch points when selecting actions with the left and right hand. Those subjects were excluded from further analyses, as this was an indication that these participants did not switch hands correctly throughout the task.

The behavioral data were processed in three steps. First, outliers were removed using Cook's distance (threshold: 3 times mean distance) (Cook, 1977), a procedure optimized for removing outliers in data containing (linear) trends. As most participants became faster over the course of the experiment, overall trends were corrected by demeaning the data every 100 trials (a block of 100 trials contained all five stimulation conditions). Finally, reaction times were indexed as $z$-scores to account for differences in mean reaction times across participants (Bush et al., 1993).

We analyzed the effects of the different stimulation conditions on the duration of the selection process separately for stimuli with orientations that afforded one grip type and stimuli with orientations that afforded two grip types. When an object affords two grip types, a choice has to be made between two competing action plans, which puts a larger demand on the process of action selection (Cisek and Kalaska, 2010; Wood and Goodale, 2011). We therefore consider trials with stimulus orientation within a 24 degree range of the switch points (maximal trial-to-trial variability in selected grip type) as "high demand" trials, identical to the procedure reported previously (Brinkman et al., 2014). In contrast, trials with stimulus orientation within 24 degrees distance of orientations orthogonal to the switch points (minimal trial-to-trial variability in selected grip type) were labeled "low demand" trials. All analysis steps were performed using custom MATLAB code (The MathWorks).

Statistical significance was assessed by means of repeated-measures ANOVA with factors "stimulation" (yes, no), "stimulation site" (ipsilateral, contralateral sensorimotor cortex), "stimulation frequency" (alpha, beta rhythm), and/or "task demand" (high, low) and post hoc pairedsample $t$ tests, using SPSS 21.

Endogenous spectral changes during movement selection. The effects of the tACS interventions on the duration of movement selection were compared with endogenous spectral changes during task performance, as measured with MEG. The MEG data were recorded previously (Brinkman et al., 2014) in an independent sample of participants who performed a movement selection task that was highly similar to the one described in this study. Across experiments, the tasks differed only in the display time of the stimuli and the response modality. Instead of an immediate response, the stimuli in the MEG study were displayed for a fixed amount of time (1500 ms), after which participants indicated with a button-press where their thumb was at the end of the simulated movement. The delayed response was introduced to prevent signals related to preparation of the response during the simulation interval, whereas the immediate response in the current task allowed for high trial density during the stimulation intervals. Task-induced changes in endogenous alpha- and beta-band power were averaged over the movement selection interval $(0-1500 \mathrm{~ms})$ for the sensorimotor cortex contralateral and ipsilateral to the grasping hand.

\section{Results}

The preferred manner in which the cylinder was grasped depended on the orientation of the stimulus and followed the biomechanical constraints of the body (Fig. 1C). When the cylinder was oriented such that multiple biomechanically plausible grasping configurations were possible, the duration of the selection process increased (paired-sample $t$ test, $t_{(32)}>8.5, p<0.01$; Fig. $1 D)$. On average, the tACS interventions slowed down movement selection (main effect of stimulation: $F_{(1,32)}=8.1, p<0.01$ ), which might be driven by stimulation of parietal cortex (discussed below). Our main observation is that, when multiple movements were considered, the effect of the tACS intervention depended on the location and frequency of stimulation (Fig. $2 A$ : interaction between tACS frequency $[10 \mathrm{~Hz}, 20 \mathrm{~Hz}]$ and stimulated hemisphere [ipsilateral, contralateral], $F_{(1,32)}=5.6, p<$ $0.05)$. Pairwise comparisons indicate that the interaction is 
A

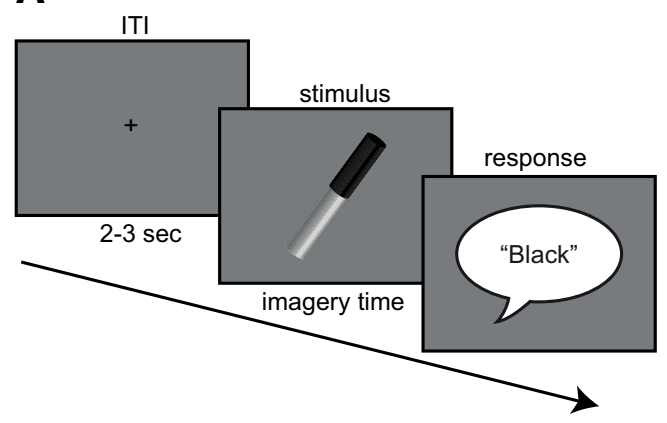

C

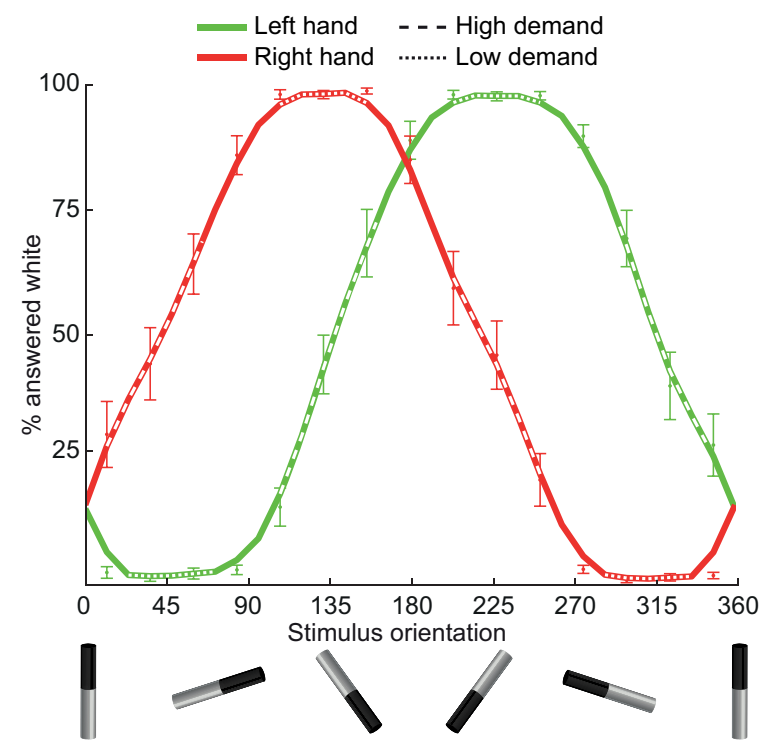

B

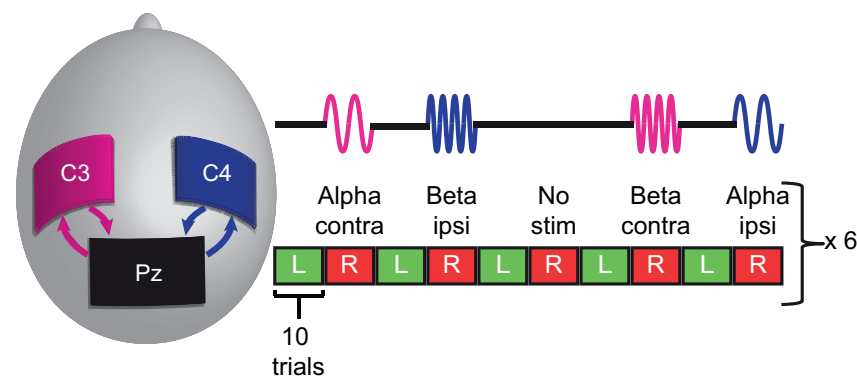

D
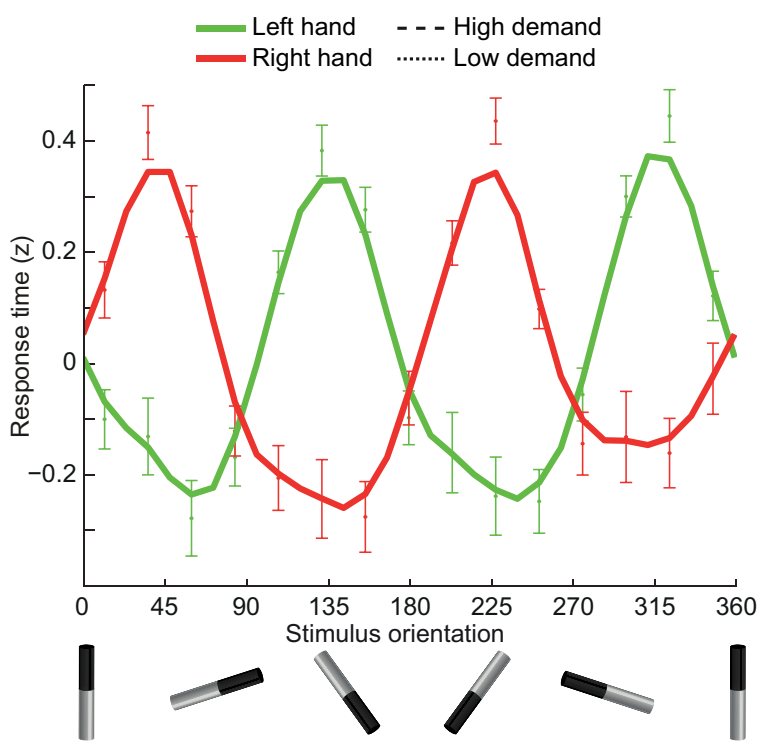

Figure 1. Experimental design and task performance. A, Participants were asked to imagine grasping the middle third of a tilted black-white cylinder ("stimulus"), which could be in 1 of 15 different orientations. As soon as they selected the movement, they indicated with a verbal response ("black" or "white") whether their thumb was on the cylinder's black or white part. ITI, Intertrial interval. $\boldsymbol{B}$, While participants selected how to grasp the tilted cylinder, oscillations in the sensorimotor cortex ipsilateral or contralateral to the grasping hand were independently modulated with short blocks ( $1 \mathrm{~min})$ of tACS at either alpha $(10 \mathrm{~Hz})$ or beta $(20 \mathrm{~Hz})$ frequency. Stimulation was only applied during right hand trials to allow for wash-out of aftereffects of the intervention. There were also right hand trials that did not involve stimulation ("no stim"), which were used for comparison with the stimulation conditions. C, Percentage of trials in which participants reported to have imagined grasping the cylinder with their thumb on the white part, as a function of cylinder orientation, plotted separately for trials involving the left and the right hand. Dotted/dashed segments of the performance curves indicate cylinder orientations that afforded a single grasping configuration (e.g., 135 degrees for right hand trials, low-demand regime) or multiple grasping configurations (e.g., 45 degrees for right hand trials, high-demand regime), respectively. Error bars indicate $\pm 1 \mathrm{SE}$. For the line plots, data points were interpolated every 12 degrees and smoothed over 3 consecutive orientations. It can be seen that the preferred manner in which the cylinder was grasped depended on its orientation and followed the biomechanical constraints of the body. $D$, Duration of action selection ( $z$-scores) as a function of cylinder orientation, plotted separately for trials involving the left and the right hand (all trials). Movement selection took $990 \pm 390$ ms (left hand; mean \pm SE) and $975 \pm 400 \mathrm{~ms}$ (right hand). Movement selection took longer (110 $\pm 20 \mathrm{~ms}$, left hand; $105 \pm 20 \mathrm{~ms}$, right hand) when the cylinder afforded two different grasping configurations (high-demand trials) than when the cylinder could be grasped in a single manner (low-demand trials). The lines of individual subjects have been realigned based on the individual high demand orientations, before averaging. Other conventions as in $\boldsymbol{C}$.

driven by faster response times in the condition where $10 \mathrm{~Hz}$ stimulation was applied to the ipsilateral hemisphere (by $22 \pm 16$ $\mathrm{ms}, 2 \%$ of average response time, compared with ipsilateral $20 \mathrm{~Hz}$ stimulation, $t_{(32)}=2.8, p<0.01$; or contralateral $10 \mathrm{~Hz}$ stimulation, $\left.t_{(32)}=2.2, p<0.05\right)$. This facilitatory effect was relative to the general slowing by tACS. The $10 \mathrm{~Hz}$ stimulation did not lead to movement selection times that were significantly faster compared with the no-stimulation condition $\left(t_{(32)}=-0.9, p=0.35\right)$. However, there are three observations that qualify the effect of 10 $\mathrm{Hz}$ stimulation as a facilitation of movement selection.

First, the pattern of behavioral effects induced by tACS closely matched the pattern of neurophysiological effects evoked during task performance in an independent group of participants. Namely, when an action was selected from multiple biomechanically plausible grasping configurations, alpha-band power increased over the ipsilateral sensorimotor cortex. In all other conditions, the spectral power in both the alpha- and beta-band decreased (Fig. 2C, modified from Brinkman et al., 2014). The probability of observing this pattern in both studies can be assessed by multiplying the probabilities of those observations within each study. To this extent, we randomly permuted task conditions within each experiment (alpha/ beta, ipsilateral/contralateral, high/low demand, 100,000 iterations per experiment), testing on each iteration whether there was a facilitatory effect (increase in spectral power or decrease of selection duration) that was contingent on the alpha-band rhythm, the ipsilateral hemisphere, and high task demands (tACS: $p=0.06$, MEG: $p=$ 0.02 ). The probability of observing these findings in both studies therefore is $<0.01$.

Second, the facilitatory effect of tACS on task performance disappeared in trials affording a single biomechanically plausible 
A

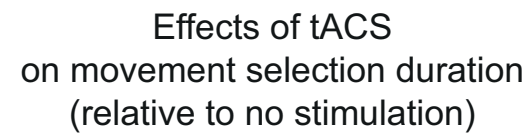

C Changes in endogenous sensorimotor rhythms

(from Brinkman et al. 2014)

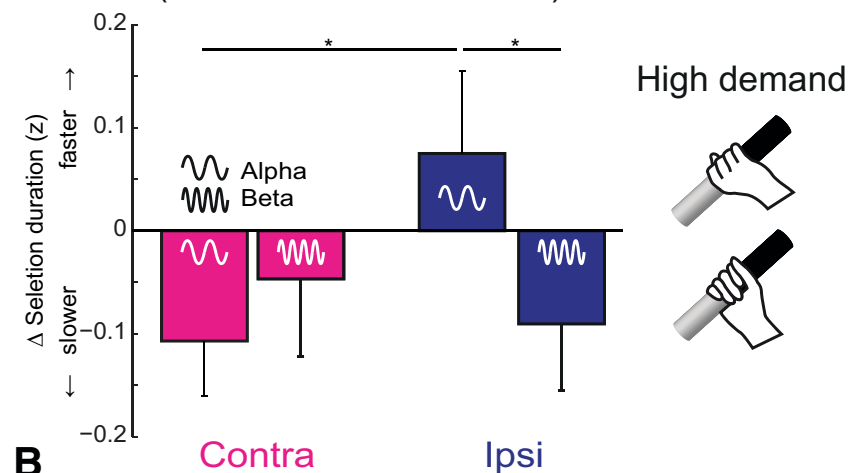

Low demand
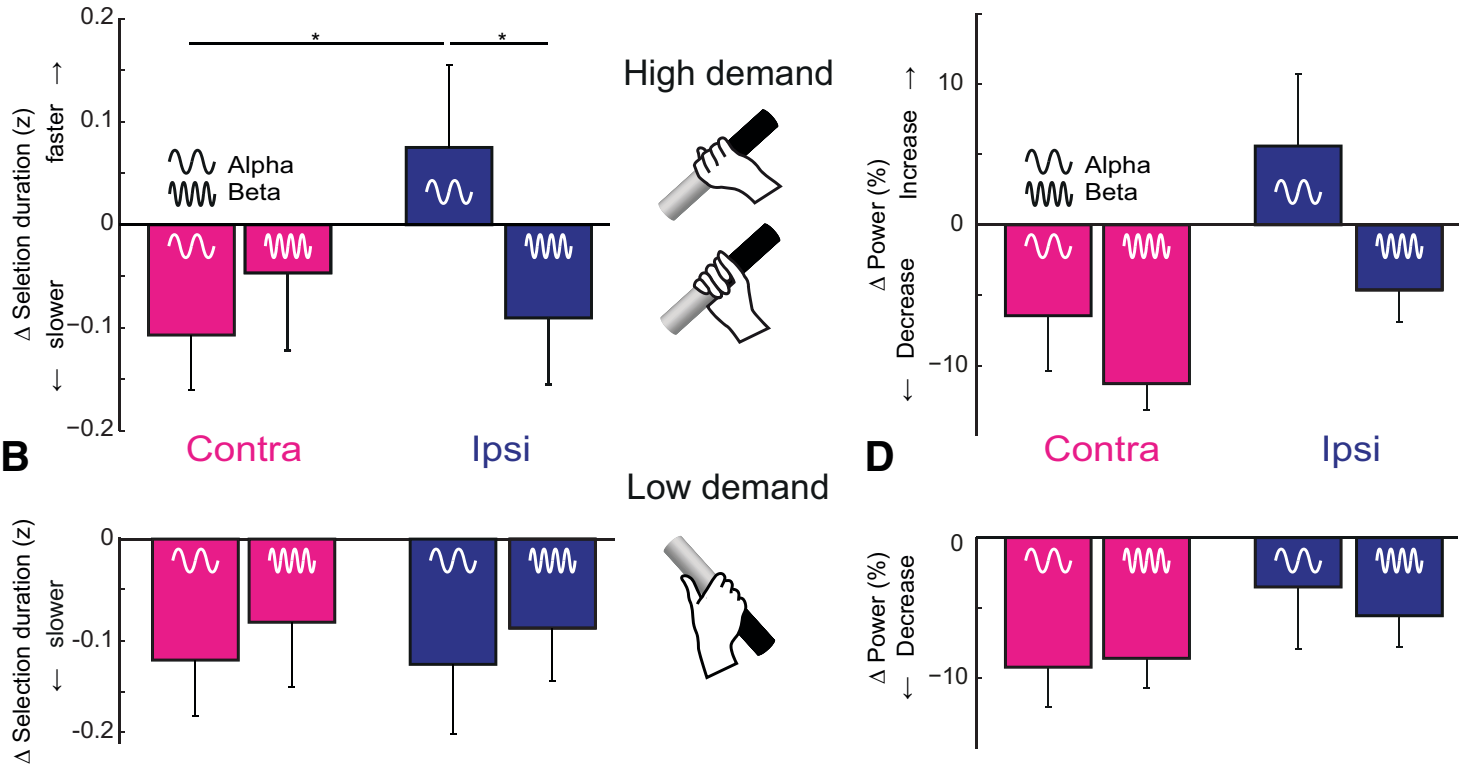

Figure 2. Effects of tACS on action selection duration. $\boldsymbol{A}, \boldsymbol{B}$, The four bars represent the effects of tACS on the duration of selecting an action (relative to no tACS, in z-scores) for the different stimulation conditions: stimulation of the contralateral (pink) or ipsilateral (blue) sensorimotor cortex at either alpha ( $10 \mathrm{~Hz})$ or beta frequency ( $20 \mathrm{~Hz}$ ), for high- and low- demand trials. During high-demand trials, action selection was faster when the sensorimotor cortex ipsilateral to the grasping hand was stimulated at $10 \mathrm{~Hz}$. Asterisks indicate the significant post hoc paired-sample $t$ tests (alpha-ipsilateral vs alpha-contralateral, $t_{(32)}=2.2, p<0.05$; alpha-ipsilateral vs beta-ipsilateral, $t_{(32)}=2.8, p<0.01$ ). $C, D$, (hanges in oscillatory power relative to a prestimulus baseline period recorded using MEG (Brinkman et al., 2014) in an independent group of participants performing the same task with a delayed manual response (same conventions as in $\boldsymbol{A}, \boldsymbol{B}$ ).

grasping configuration (Fig. 2B). In that circumstance, tACS prolonged task performance irrespectively of stimulation frequency or stimulation site (Fig. $2 B$; main effect of stimulation: $F_{(1,32)}=$ 5.0, $p<0.05$; interaction of frequency and hemisphere: $F_{(1,32)}<$ $0.01, p>0.9)$, matching the pattern of neurophysiological effects evoked during task performance (Fig. 2D).

Third, the facilitatory effect of tACS was bound to the stimulation epoch, excluding the possibility that the effect is driven by homeostatic meta-plasticity phenomena associated with prolonged tACS interventions (Vossen et al., 2015). Namely, trials following tACS epochs had slower responses than trials following no-stimulation epochs (main effect of stimulation: $F_{(1,32)}=15.0$, $p<0.01$ ), but these effects did not depend on stimulation frequency, stimulation site, or task demands (Fig. 3). These three observations indicate that facilitation of movement selection by $10 \mathrm{~Hz}$ stimulation is the most parsimonious explanation of the data.

\section{Discussion}

This study shows that tACS affects the duration of movement selection and that the effects depend both on task demands and on the side and frequency of stimulation. On average, tACS increased the duration of movement selection, which is possibly related to stimulation of parietal regions. Although the current montage has been shown effective in modulating sensorimotor regions (Feurra et al., 2011, 2013), the tACS interventions also likely affected parietal cortex (Rampersad et al., 2014). In these regions, the spectral power in both alpha- and beta-bands decreases bilaterally during movement selection (Brinkman et al., 2014). It is therefore possible that interference with the endogenous power decreases in parietal regions has contributed to the general slowing effect of the tACS intervention.
Above and beyond the general slowing effect, local application of a $10 \mathrm{~Hz}$ rhythm led to faster responses when multiple movements were considered. The fact that we observe behavioral benefits selectively when multiple movements are considered suggests that the tACS intervention facilitates the resolution of competition between alternative movements. This finding matches the task-induced spectral changes during movement selection, as endogenous alpha-band power increases exclusively in the ipsilateral hemisphere when multiple movements are considered. It is therefore plausible that the facilitatory effect of tACS on task performance was mediated by an enhancement of endogenous alpha-band power in the sensorimotor cortex ipsilateral to the grasping hand. By the same token, exogenous application of 10 and $20 \mathrm{~Hz}$ oscillations over the sensorimotor cortex contralateral to the grasping hand likely hampered task performance by counteracting the endogenous disinhibition of task-relevant populations.

The effects of $10 \mathrm{~Hz}$ and $20 \mathrm{~Hz}$ tACS might be driven by the same neurophysiological mechanism, namely, a modulation of the dynamic shunting inhibition exerted by GABAergic interneurons over a local neuronal ensemble (Jensen and Mazaheri, 2010). The magnitude of this dynamic inhibition is modulated by the amplitude of low-frequency oscillations in the local neural populations (Miller et al., 2010, 2012). It is therefore reasonable to assume that the effects of the tACS interventions are mediated through an increase of the dynamic inhibition of the sensorimotor cortex.

How does inhibition of neuronal population in the ipsilateral sensorimotor cortex facilitate movement selection? Here we provide three possible explanations. First, it is possible that the behavioral benefits are mediated through a release of interhemispheric inhibition (Ferbert et al., 1992; Kobayashi et al., 2004). Potentiation of the alpha-band rhythm in the sensorimotor cortex ipsilateral to the 

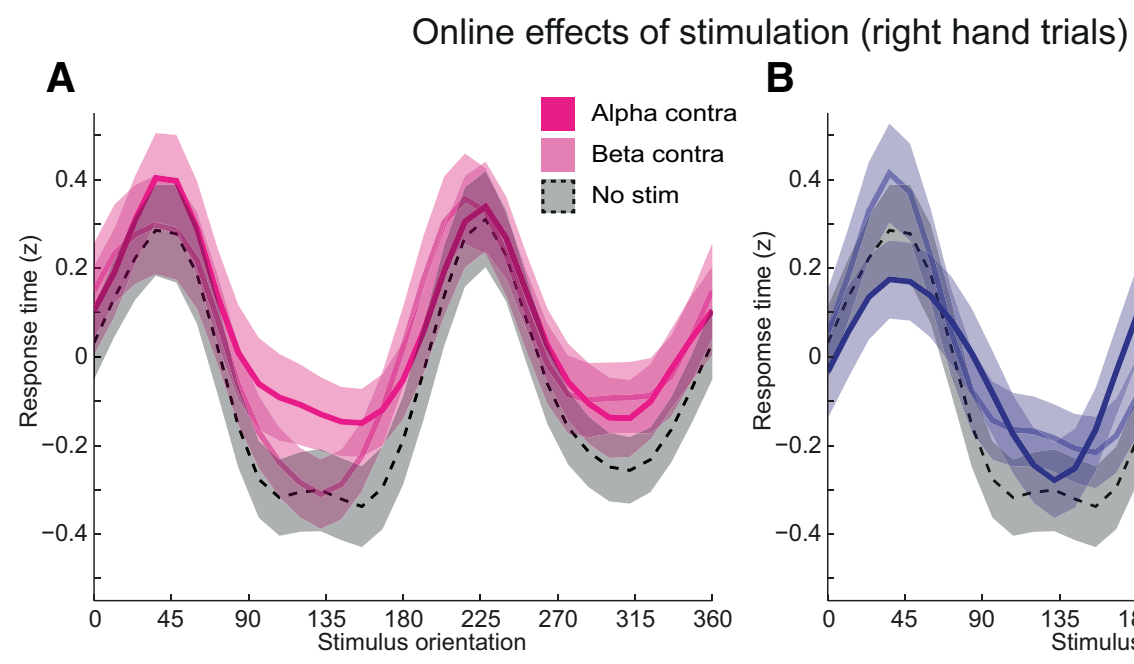

\section{B}
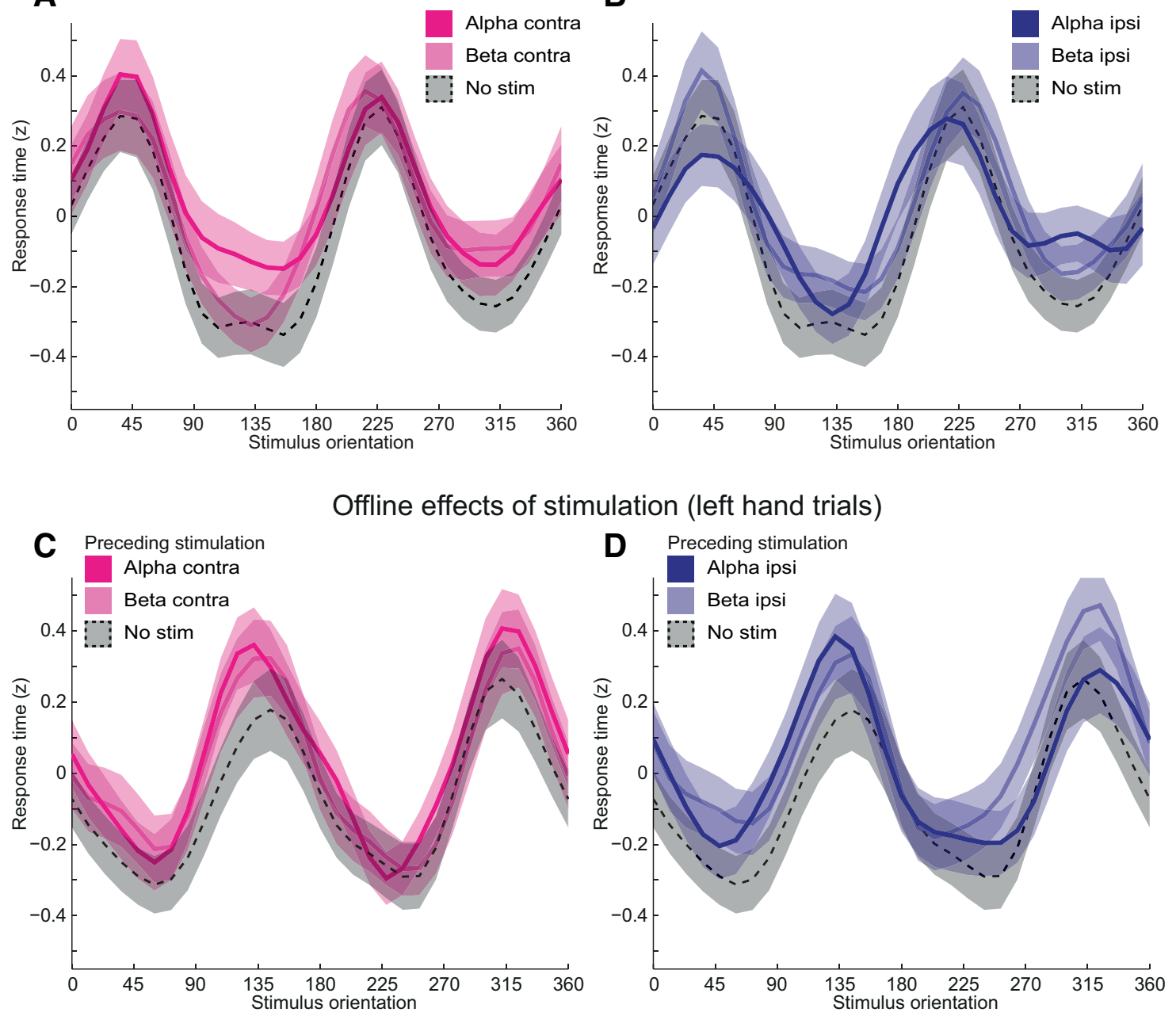

Figure 3. Online and offline effects of $t A C S$ on action selection duration. $A, B$, Duration of action selection ( $z$-scores) as a function of cylinder orientation for trials involving the right hand. Curves represent action selection duration during trials involving tACS to either the contralateral (pink) or the ipsilateral (blue) sensorimotor cortex, at $10 \mathrm{~Hz}$ (bold lines), $20 \mathrm{~Hz}$ (light lines), or without stimulation (dotted lines). Other conventions as in Figure 1D. It can be seen that the tACS intervention did not alter the dependency of action selection on biomechanical constraints, an indication that the faster response times following $10 \mathrm{~Hz}$ stimulation over the ipsilateral sensorimotor cortex during high-demand trials did not arise from a strategic shift toward the selection of a stereotypical grasping configuration. C, D, Same conventions as above, for trials involving the left hand, when no stimulation was applied. These curves were sorted according to the stimulation condition occurring in the preceding block, involving the right hand (see Fig. 1). This sorting procedure was applied to investigate potential offline effects induced by the tACS intervention. It can be seen that trials following tACS epochs had slower responses than trials following no-stimulation epochs (main effect of stimulation: $F_{(1,32)}=15.0, p<0.0005$ ), but these effects did not depend on the frequency or the site of stimulation, or on task demand.

grasping hand may suppress the inhibitory drive to the contralateral homolog. The tACS intervention may facilitate the disinhibition of sensorimotor ensembles in the contralateral hemisphere that constitute the neuronal search space of potential movements. Disinhibition of the neuronal search space might facilitate the resolution of competition between alternative movements, leading to faster movement selection times. A second possibility is that the alphaband rhythm downregulates local neuronal population involved in producing solutions that violate task instructions (e.g., grasping the object with the noninstructed hand). This may be particularly relevant when the stimulus affords two ways in which it can be grasped with the instructed hand (high demand) because, in those trials, the same stimulus can be grasped only in one manner with the noninstructed hand. It is possible that this unique movement of the noninstructed hand is automatically considered, even though choosing this movement would violate task instruction. Suppression of this tendency may be facilitated by the tACS intervention, thereby improving task performance. Third, the alpha rhythm may suppress the processing of somatosensory input to the noninstructed effector to reallocate computational resources to the grasping hand. The reallocation of computational resources may be particularly relevant when the task is demanding and multiple movements are considered.

By the same token, the current findings provide a neurophysiological mechanism for the known activity-dependent reduction of cortical excitability in the motor cortex ipsilateral to a taskrelevant effector (Liepert et al., 2001; Perez and Cohen, 2008; Liang et al., 2014). This interpretation is relevant because it extends to the motor system the general notion of "pulsed inhibition" through which alpha-band activity is thought to adaptively gate neuronal processes across several sensory cortices $(2,17)$. This interpretation also adds specificity to recent observations linking administration of $20 \mathrm{~Hz}$ oscillations over the motor cortex to reduced corticospinal excitability and movement velocity of the contralateral hand (Pogosyan et al., 2009; Feurra et al., 2011, 2013; Wach et al., 2013). Namely, the current findings sug- 
gest that those interference effects arise from the imposition of a frequency-specific counterweight to the endogenous disinhibition of task-relevant neuronal populations during the selection stage of a movement. Furthermore, the findings corroborate the notion that tACS effects are conditional on the presence of taskrelated endogenous oscillatory activity (Ali et al., 2013; Feurra et al., 2013; Schmidt et al., 2014).

Apart from providing insight in the roles of the sensorimotor rhythms, the current findings are of potential interest for clinical applications of noninvasive brain stimulation to improve rehabilitation after neural damage (Fregni et al., 2005; Schlaug et al., 2008). It has been suggested that recovery of the affected hemisphere is facilitated by a release of interhemispheric inhibition from the unaffected hemisphere (Traversa et al., 1997; Liepert et al., 1998; Wolf et al., 2013). Potentiation of the alpha-band rhythm in the unaffected hemisphere may have similar effects, mediated by modulations of endogenous neural circuits. As such, $10 \mathrm{~Hz}$ tACS to the unaffected hemisphere has the potential to improve recovery, in particular if applied when endogenous alpha-band activity is high, such as during movement selection (Brinkman et al., 2014).

\section{Interpretational issues}

This study shows the potential for $10 \mathrm{~Hz}$ stimulation to enhance performance. By the same token, it also shows that the intervention needs to be further optimized to effectively facilitate behavior. In particular, the general slowing that was observed in this study needs to be diminished, to assess whether $10 \mathrm{~Hz}$ stimulations lead to behavioral improvement relative to no stimulation. This can possibly be achieved by using electrode montages that affect parietal regions to a lesser extent (e.g., by placing the electrode at locations anterior and posterior of the motor hotspot) (Rampersad et al., 2014). Moreover, stimulating at the peak frequencies of endogenous alpha rhythms of individual subjects might increase the magnitude of the facilitatory effect.

Based on the task-induced spectral changes, we hypothesized that the effects of the tACS interventions on movement selection would depend on the hemisphere that was stimulated, regardless of selection demands and/or stimulation frequency. However, that was only the case when stimulation was applied at $10 \mathrm{~Hz}$ and when task demands were high. The lack of lateralized effects in other stimulation conditions might be accounted for by the low amount of endogenous spectral power in those conditions. Namely, apart from the increase in endogenous alpha-band power over the ipsilateral sensorimotor cortex when task demands were high, the task induced a decrease in spectral power in both frequency bands in all other conditions. Given that the exogenous rhythms superimposed by the tACS intervention amplifies endogenous oscillatory activity (Ozen et al., 2010; Ali et al., 2013; Feurra et al., 2013; Schmidt et al., 2014), the tACS intervention may have been less effective when the endogenous oscillatory activity was low, possibly leading to the absence of clear lateralized effects of the intervention in those conditions.

Despite the presence of clear electrophysiological markers of neural changes evoked by task performance (Fig. 2C), this study lacks direct evidence that the tACS induced local modulations of those rhythms. Acquiring that evidence would require the recording of electrophysiological signals during the application of tACS, an experimental setup that has been implemented with invasive recordings (Ozen et al., 2010; Ali et al., 2013; Schmidt et al., 2014; Alagapan et al., 2016). Simultaneous noninvasive tACSMEG/EEG is becoming available in humans (Helfrich et al., 2014, 2015; Neuling et al., 2015; Witkowski et al., 2015) but can entail reduced sensitivity and specificity. For instance, this study achieves high trial density during each tACS epoch by measuring behavioral consequences of the tACS intervention with an immediate verbal report. A simultaneous tACS-MEG setup would have required delayed reports (Brinkman et al., 2014) and, consequently, less reliable estimates of task and intervention effects. By using experimental conditions optimized for showing the presence of movement selection facilitation during $10 \mathrm{~Hz}$ ipsilateral sensorimotor stimulation, this study opens the way to characterize both local and system-level neurophysiological changes evoked by tACS using a combined tACS-MEG/EEG setup.

In conclusion, this study provides causal evidence for distinct contributions of sensorimotor alpha- and beta-band rhythms to movement selection. The findings suggest that $10 \mathrm{~Hz}$ tACS facilitates movement selection when multiple movements are considered with the hand ipsilateral to the stimulated hemisphere. This offers two elements of general relevance. First, the finding suggests that, in the sensorimotor system, the alpha rhythm operates by inhibiting neuronal populations that could interfere with movement selection. This observation functionally differentiates alpha-band oscillations from the beta rhythm, known to govern the (dis)inhibition of neuronal populations relevant for the current task. Second, the finding offers a neurophysiologically grounded account of how human performance can be enhanced with noninvasive stimulation techniques. Namely, by targeting endogenous inhibitory rhythms evoked by task performance, tACS may facilitate the exploration of the search space of solutions that need to be considered when solving a motor task, leading to enhanced performance.

\section{References}

Alagapan S, Schmidt SL, Lefebvre J, Hadar E, Shin HW, Fröhlich F (2016) Modulation of cortical oscillations by low-frequency direct cortical stimulation is state-dependent. PLOS Biol 14:e1002424. CrossRef Medline

Ali MM, Sellers KK, Fröhlich F (2013) Transcranial alternating current stimulation modulates large-scale cortical network activity by network resonance. J Neurosci 33:11262-11275. CrossRef Medline

Brinkman L, Stolk A, Dijkerman HC, de Lange FP, Toni I (2014) Distinct roles for alpha- and beta-band oscillations during mental simulation of goal-directed actions. J Neurosci 34:14783-14792. CrossRef Medline

Brown P (2007) Abnormal oscillatory synchronisation in the motor system leads to impaired movement. Curr Opin Neurobiol 17:656-664. CrossRef Medline

Bush LK, Hess U, Wolford G (1993) Transformations for within-subject designs: a Monte Carlo investigation. Psychol Bull 113:566-579. CrossRef Medline

Cisek P, Kalaska JF (2010) Neural mechanisms for interacting with a world full of action choices. Annu Rev Neurosci 33:269-298. CrossRef Medline

Cook RD (1977) Detection of influential observation in linear regression. Technometrics 19:15-18. CrossRef

DaSilva AF, Volz MS, Bikson M, Fregni F (2011) Electrode positioning and montage in transcranial direct current stimulation. J Vis Exp 23:pii2744. CrossRef Medline

Davidson PR, Wolpert DM (2005) Widespread access to predictive models in the motor system: a short review. J Neural Eng 2:S313-S319. CrossRef Medline

de Lange FP, Hagoort P, Toni I (2005) Neural topography and content of movement representations. J Cogn Neurosci 17:97-112. CrossRef Medline

de Lange FP, Jensen O, Bauer M, Toni I (2008) Interactions between posterior gamma and frontal alpha/beta oscillations during imagined actions. Front Hum Neurosci 2:1-12. CrossRef Medline

Dijkerman HC, McIntosh RD, Schindler I, Nijboer TC, Milner AD (2009) Choosing between alternative wrist postures: action planning needs perception. Neuropsychologia 47:1476-1482. CrossRef Medline

Donoghue JP, Sanes JN, Hatsopoulos NG, Gaál G, Nicolai C Von, Engler G, Sharott A, Engel AK, Moll CK, Siegel M, Sayegh PF, Hawkins KM, Hoffman KL, Sergio LE (1998) Neural discharge and local field potential oscillations in primate motor cortex during voluntary movements neural 
discharge and local field potential oscillations in primate motor cortex during voluntary movements. J Neurophysiol 79:159-173. Medline

Ferbert A, Priori A, Rothwell JC, Day BL, Colebatch JG, Marsden CD (1992) Interhemispheric inhibition of the human motor cortex. J Physiol 453: 525-546. CrossRef Medline

Feurra M, Bianco G, Santarnecchi E, Del Testa M, Rossi A, Rossi S (2011) Frequency-dependent tuning of the human motor system induced by transcranial oscillatory potentials. J Neurosci 31:12165-12170. CrossRef Medline

Feurra M, Pasqualetti P, Bianco G, Santarnecchi E, Rossi A, Rossi S (2013) State-dependent effects of transcranial oscillatory currents on the motor system: what you think matters. J Neurosci 33:17483-17489. CrossRef Medline

Fregni F, Boggio PS, Mansur CG, Wagner T, Ferreira MJ, Lima MC, Rigonatti SP, Marcolin MA, Freedman SD, Nitsche MA, Pascual-Leone A (2005) Transcranial direct current stimulation of the unaffected hemisphere in stroke patients. Neuroreport 16:1551-1555. CrossRef Medline

Georgopoulos AP, Carpenter AF (2015) Coding of movements in the motor cortex. Curr Opin Neurobiol 33:34-39. CrossRef Medline

Greenhouse I, Sias A, Labruna L, Ivry RB (2015) Nonspecific inhibition of the motor system during response preparation. J Neurosci 35:1067510684. CrossRef Medline

Helfrich RF, Schneider TR, Rach S, Trautmann-Lengsfeld SA, Engel AK, Herrmann CS (2014) Entrainment of brain oscillations by transcranial alternating current stimulation. Curr Biol 24:333-339. CrossRef Medline

Helfrich RF, Herrmann CS, Engel AK, Schneider TR (2015) Different coupling modes mediate cortical cross-frequency interactions. Neuroimage 2015:piiS1053-8119. CrossRef Medline

Herrmann CS, Rach S, Neuling T, Strüber D (2013) Transcranial alternating current stimulation: a review of the underlying mechanisms and modulation of cognitive processes. Front Hum Neurosci 7:279. CrossRef Medline

Jeannerod M (1995) Mental imagery in the motor context. Neuropsychologia 33:1419-1432. CrossRef Medline

Jeannerod M, Decety J (1995) Mental motor imagery: a window into the representational stages of action. Curr Opin Neurobiol 5:727-732. CrossRef Medline

Jensen O, Mazaheri A (2010) Shaping functional architecture by oscillatory alpha activity: gating by inhibition. Front Hum Neurosci 4:1-8. CrossRef Medline

Kobayashi M, Hutchinson S, Théoret H, Schlaug G, Pascual-Leone A (2004) Repetitive TMS of the motor cortex improves ipsilateral sequential simple finger movements. Neurology 62:91-98. CrossRef Medline

Laakso I, Hirata A (2013) Computational analysis shows why transcranial alternating current stimulation induces retinal phosphenes. J Neural Eng 10:1-9. CrossRef Medline

Leocani L, Cohen LG, Wassermann EM, Ikoma K, Hallett M (2000) Human corticospinal excitability evaluated with transcranial magnetic stimulation during different reaction time paradigms. Brain 123:1161-1173. CrossRef Medline

Liang N, Funase K, Takahashi M, Matsukawa K, Kasai T (2014) Unilateral imagined movement increases interhemispheric inhibition from the contralateral to ipsilateral motor cortex. Exp Brain Res 232:1823-1832. CrossRef Medline

Liepert J, Miltner WH, Bauder H, Sommer M, Dettmers C, Taub E, Weiller C (1998) Motor cortex plasticity during constraint, induced movement therapy in stroke patients. Neurosci Lett 250:5-8. CrossRef Medline

Liepert J, Dettmers C, Terborg C, Weiller C (2001) Inhibition of ipsilateral motor cortex during phasic generation of low force. Clin Neurophysiol 112:114-121. CrossRef Medline

McFarland DJ, Miner LA, Vaughan TM, Wolpaw JR (2000) Mu and beta rhythm topographies during motor imagery and actual movements. Brain Topogr 12:177-186. CrossRef Medline

Miller KJ, Hermes D, Honey CJ, Sharma M, Rao RP, den Nijs M, Fetz EE, Sejnowski TJ, Hebb AO, Ojemann JG, Makeig S, Leuthardt EC (2010) Dynamic modulation of local population activity by rhythm phase in human occipital cortex during a visual search task. Front Hum Neurosci 4:197. CrossRef Medline

Miller KJ, Foster BL, Honey CJ (2012) Does rhythmic entrainment represent a generalized mechanism for organizing computation in the brain? Front Comput Neurosci 6:85. CrossRef Medline

Milner AD, Dijkerman HC, Pisella L, McIntosh RD, Tilikete C, Vighetto A,
Rossetti Y (2001) Grasping the past. delay can improve visuomotor performance. Curr Biol 11:1896-1901. CrossRef Medline

Murakami M, Mainen ZF (2015) Preparing and selecting actions with neural populations: toward cortical circuit mechanisms. Curr Opin Neurobiol 33:40-46. CrossRef Medline

Murthy VN, Fetz EE (1992) Coherent 25- to 35-Hz oscillations in the sensorimotor cortex of awake behaving monkeys. Proc Natl Acad Sci U S A 89:5670-5674. CrossRef Medline

Neuling T, Ruhnau P, Fuscà M, Demarchi G, Herrmann CS, Weisz N (2015) Friends, not foes: magnetoencephalography as a tool to uncover brain dynamics during transcranial alternating current stimulation. Neuroimage 118:406-413. CrossRef Medline

Osipova D, Hermes D, Jensen O (2008) Gamma power is phase-locked to posterior alpha activity. PLoS One 3:1-7. CrossRef Medline

Ozen S, Sirota A, Belluscio MA, Anastassiou CA, Stark E, Koch C, Buzsáki G (2010) Transcranial electric stimulation entrains cortical neuronal populations in rats. J Neurosci 30:11476-11485. CrossRef Medline

Perez MA, Cohen LG (2008) Mechanisms underlying functional changes in the primary motor cortex ipsilateral to an active hand. J Neurosci 28: 5631-5640. CrossRef Medline

Pogosyan A, Gaynor LD, Eusebio A, Brown P (2009) Boosting cortical activity at beta-band frequencies slows movement in humans. Curr Biol 19:1637-1641. CrossRef Medline

Rampersad SM, Janssen AM, Lucka F, Aydin Ü, Lanfer B, Lew S, Wolters CH, Stegeman DF, Oostendorp TF (2014) Simulating transcranial direct current stimulation with a detailed anisotropic human head model. IEEE Trans Neural Syst Rehabil Eng 22:441-452. CrossRef Medline

Reato D, Rahman A, Bikson M, Parra LC (2013) Effects of weak transcranial alternating current stimulation on brain activity-a review of known mechanisms from animal studies. Front Hum Neurosci 7:687. CrossRef Medline

Rosenbaum DA, Halloran ES, Cohen RG (2006) Grasping movement plans. Psychon Bull Rev 13:918-922. CrossRef Medline

Schlaug G, Renga V, Nair D (2008) Transcranial direct current stimulation in stroke recovery. Arch Neurol 65:1571-1576. CrossRef Medline

Schmidt SL, Iyengar AK, Foulser AA, Boyle MR, Fröhlich F (2014) Endogenous cortical oscillations constrain neuromodulation by weak electric fields. Brain Stimul 7:878-889. CrossRef Medline

Shadmehr R, Krakauer JW (2008) A computational neuroanatomy for motor control. Exp Brain Res 185:359-381. CrossRef Medline

Traversa R, Cicinelli P, Bassi A, Rossini PM, Bernardi G (1997) Mapping of motor cortical reorganization after stroke: a brain stimulation study with focal magnetic pulses. Stroke 28:110-117. CrossRef Medline

Verhagen L, Dijkerman HC, Grol MJ, Toni I (2008) Perceptuo-motor interactions during prehension movements. J Neurosci 28:4726-4735. CrossRef Medline

Verhagen L, Dijkerman HC, Medendorp WP, Toni I (2012) Cortical dynamics of sensorimotor integration during grasp planning. J Neurosci 32:4508-4519. CrossRef Medline

Vossen A, Gross J, Thut G (2015) Alpha power increase after transcranial alternating current stimulation at alpha frequency ( $\alpha$-tACS) reflects plastic changes rather than entrainment. Brain Stimul 8:499-508. CrossRef Medline

Voytek B, Canolty RT, Shestyuk A, Crone NE, Parvizi J, Knight RT (2010) Shifts in gamma phase-amplitude coupling frequency from theta to alpha over posterior cortex during visual tasks. Front Hum Neurosci 4:191. CrossRef Medline

Wach C, Krause V, Moliadze V, Paulus W, Schnitzler A, Pollok B (2013) Effects of $10 \mathrm{~Hz}$ and $20 \mathrm{~Hz}$ transcranial alternating current stimulation (tACS) on motor functions and motor cortical excitability. Behav Brain Res 241:1-6. CrossRef Medline

Witkowski M, Cossio EG, Chander BS, Braun C, Birbaumer N, Robinson SE, Soekadar SR (2015) Mapping entrained brain oscillations during transcranial alternating current stimulation (tACS). Neuroimage 2015: piiS1053-8119(15)00934-9. CrossRef Medline

Wolf SL, Winstein CJ, Miller JP, Morris D (2013) Effect of constraintinduced movement therapy on upper extremity function 3 to 9 months after stroke. J Am Med Assoc 296:2095-2104. CrossRef Medline

Wolpert DM, Ghahramani Z (2000) Computational principles of movement neuroscience. Nat Neurosci 3 [Suppl]:1212-1217. CrossRef Medline

Wood DK, Goodale MA (2011) Selection of wrist posture in conditions of motor ambiguity. Exp Brain Res 208:607-620. CrossRef Medline

Zimmermann M, Toni I, de Lange FP (2013) Body posture modulates action perception. J Neurosci 33:5930-5938. CrossRef Medline 